\title{
Phenotypic differences in African Americans with Prader-Willi syndrome
}

\author{
Louanne Hudgins, MD, Joseph S. Geer, MD, and Suzanne B. Cassidy, MD
}

\begin{abstract}
We report on 10 African Americans with Prader-Willi syndrome whose features differ from those of white patients with this condition. Growth is less affected, hand and foot lengths usually are normal, and the facies are atypical; this may lead to underdiagnosis in this population.
\end{abstract} We encourage clinicians to recognize these phenotypic differences so that diagnosis is not overlooked.

Prader-Willi syndrome (PWS), which has a prevalence of 1 per 10,000 to 1 per 15,000 people, is associated with hypotonia, hypogonadism, developmental and growth deficiencies including small hands and feet, behavioral abnormalities, and characteristic facial features that include narrow face or bifrontal diameter, almond-shaped eyes, and a smallappearing mouth with thin upper lip and down-turned corners. ${ }^{1}$ Diagnostic criteria have been developed ${ }^{1}$ and a single diagnostic laboratory test, methylation analysis at SNRPN (long arm of chromosome 15), can be used to identify all cases. ${ }^{2}$ However, diagnostic suspicion still rests with the clinician, who is often the pediatrician, and the proportion of African American patients who have been diagnosed is low. We present the clinical findings in 10 African Americans with Prader-Willi syndrome, compare those with the findings described in four individuals from the literature, and describe how they differ from those in white patients with this condition.

\section{METHODS}

Five African American individuals were identified through the PWS Clinic at the University of Connecticut Health Center, four through the PWS Clinic at Case Western Reserve University, and one through the Greenwood Genetics Center. The five females (cases 1-5) and five males (cases 6-10) ranged in age from 9 months to 42 years of age. The diagnosis was made based on clinical history and physical examination, and was confirmed by diagnostic testing in all 10 patients (Table 1). Special attention was paid to growth parameters, including height, hand and foot length, and craniofacial dysmorphism because they are the two areas in which the African American patients seemed to differ from white patients. Height, hand length, and foot length measurements were plotted on standard growth curves. ${ }^{3-5}$

\section{RESULTS}

Anthropometric data are summarized in Table 1. Three of the five females (cases 1,2, and 4) exhibited heights within the normal range at

From the Division of Genetics and Congenital Defects, Department of Pediatrics, University of Washington School of Medicine and Children's Hospital and Regional Medical Center, Seattle, Washington; the Greenwood Genetics Center, Greenwood, South Carolina; and the Department of Genetics and Center for Human Genetics, Case Western Reserve University and University Hospitals of Cleveland, Cleveland, $\mathrm{OH}$

Address correspondence to: Louanne Hudgins, MD, Division of Genetics and Congenital Defects/CH-25, Children's Hospital and Regional Medical Center, 4800 Sand Point Way, Seattle,WA 98105-0371.E-mail: lhudgins@u.washington.edu

01998 Genetics in Medicine. All rights reserved.1098-3600\$0.00
6,10 , and 24 years, respectively. All but one (case 3 ) had hand and foot lengths which were within the normal range, including one patient (case 5) who exhibited short stature.

The five male patients were generally younger than the females. Cases 6,8 , and 9 exhibited stature within the normal range at ages 9 months, 3 years, and 10 years, respectively. All five males had hand and foot lengths within the normal range, although the patients in cases 7 and 10 had short stature. The patient in case 10 is interesting because his hands are actually quite large ( $>97$ th percentile) and his foot length is average for adult males.

None of the five females we evaluated demonstrated the typical craniofacial features seen in PWS (cases 1-5, Fig. 1). In particular, none had narrow faces or the characteristic mouth. Of the five males (case 6 not shown because of lack of consent; cases 7-10, Fig. 1), only the patient in case 8 has the typical facial appearance.

\section{DISCUSSION}

We report on our experience with 10 African American patients with PWS. These patients had many findings consistent with PWS, such as hypotonia, genital hypoplasia/poor pubertal development, excessive eating and obesity, and developmental and behavioral abnormalities. However, as a group they had a lower frequency of typical facial appearance, short stature, and small hands and feet. None of the patients whose family members were available had altered pigmentation, although hypopigmentation is common in patients with PWS because of deletion. In general, PWS was diagnosed in males at a somewhat younger age, possibly because of their more obvious hypogenitalism.

The typical craniofacial features described in PWS, narrow face or bifrontal diameter, almond-shaped eyes, small-appearing mouth with thin upper lip and down-turned corners, seem to be less evident in our African American patients than in the white patients. This is also true for the individuals described in the three previous reports of African Americans with Prader-Willi syndrome. Of the patients reported by Golden et al., 6 the patient in case 1 was not described as being dysmorphic and, in our opinion, her photograph was not typical of PWS. The patient in case 2 was described as having a "narrow-appearing bifrontal diameter and almond shaped eyes" which were difficult to evaluate in the photograph because the subject was wearing eyeglasses. Neither had the typical mouth. The female reported by Butler et al. ${ }^{7}$ was described as having "full cheeks and chin" and "almond-shaped eyes." Unfortunately no photograph was published. Norman ${ }^{8}$ described his subject as having an "unusually narrow" forehead and "almond shaped" eyes. No photograph was published. Only 1 of our 10 African American subjects had the typical craniofacial features of PWS (case 8). Ethnic background influences craniofacial development and is presumably responsible for these differences.

In addition, hand and foot lengths seem to be less affected in African Americans than in other patients with PWS. One of the patients reported by Golden et al. ${ }^{6}$ was described as having "small hands and feet" and another patient's hands and feet were "not notably small." The patient reported by Butler et al. ${ }^{7}$ had a hand length at the third percentile for age. The patient reported by Norman ${ }^{8}$ was described as having "acromicria," although no measurements were published. Only 1 of our 10 


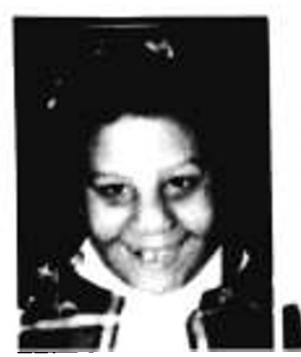

Case 1

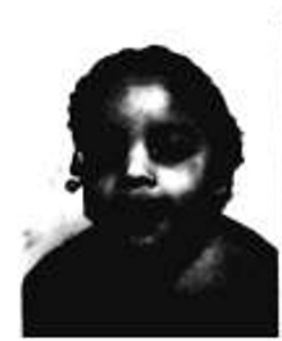

Case 7

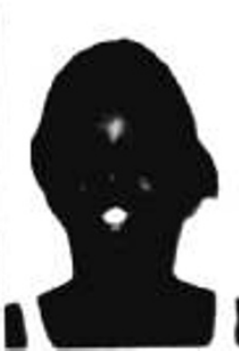

Case 2

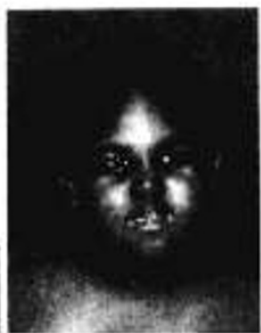

Case 8

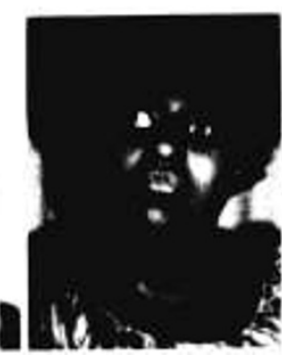

Case 3

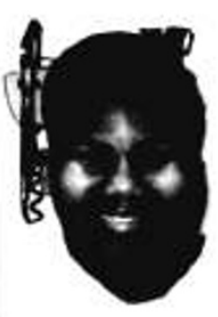

Case 9

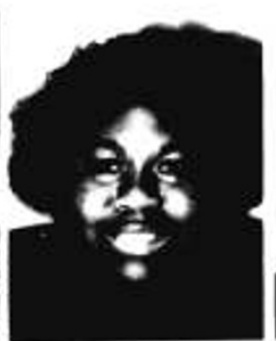

Case 4

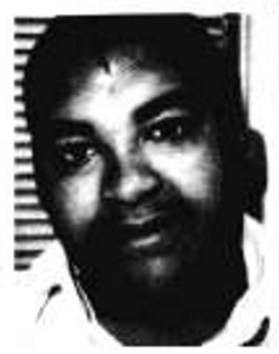

Case 10

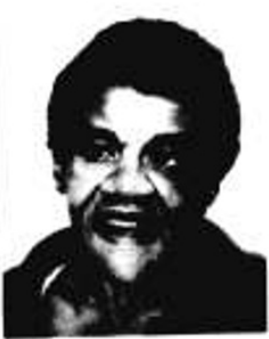

Case 5

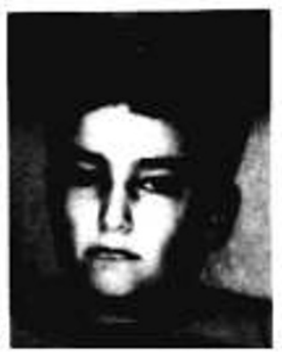

Typical PWS

Fy. 1 Facial features of nine African American patients with PWS and one white patient with typical PWS features (case 6 not shown).

Table 1

Growth data for African-American PWS patients ${ }^{a}$

\begin{tabular}{|c|c|c|c|c|c|}
\hline & Age & Diagnostic testing & Height (\%) & Hand length (\%) & Foot length (\%) \\
\hline Case I & $6 \mathrm{yr}$ & Deletion & $75-90$ & 97 & $3-25$ \\
\hline Case 2 & $10 \mathrm{yr}$ & Deletion & $10-25$ & $3-25$ & $3-25$ \\
\hline Case 3 & $18 \mathrm{yr}$ & Deletion & $<5\left(10^{1} / 2 y r\right)$ & $<3(91 / 2 y r)$ & \\
\hline Case 4 & $24 \mathrm{yr}$ & Deletion & 5 & $25-50$ & $50-75$ \\
\hline Case 5 & $42 \mathrm{yr}$ & Deletion & $<5(111 / 2 \mathrm{yr})$ & $3-25$ & 25 \\
\hline Case 6 & $9 \mathrm{mo}$ & Deletion & $5-10$ & 50 & \\
\hline Case 7 & $20 \mathrm{mo}$ & Deletion & $<5(9 \mathrm{mo})$ & $3-25$ & 3 \\
\hline Case 8 & $3 \mathrm{yr}$ & UPD & $25-50$ & 50 & 50 \\
\hline Case 9 & $10 \mathrm{yr}$ & Deletion & $25-50$ & $25-50$ & 50 \\
\hline Case 10 & $17 \mathrm{yr}$ & Deletion & $<5(14 \mathrm{yr})$ & $>97$ & 50 \\
\hline
\end{tabular}

UPD, uniparental disomy.

${ }^{a}$ Ages in parentheses represent the age for which the value is at the 50th percentile, i.e., height age.

patients had small hands and three of the four adult subjects (cases 4 , 5 , and 10) had normal hand and foot lengths; although two of them exhibited short stature (cases 5 and 10). Almost all adult white patients with PWS had short hands and feet. ${ }^{9}$ Anthropometric data for African American children were published in Vital and Health Statistics in 1974 in a monograph titled "Body Dimensions and Proportions, White and Negro Children 6-11 Years."10 The authors found no significant difference in height between white and African American children in that age group, but noted that African American children had larger hands and feet. Normative data are not available for older African American individuals, to our knowledge. Our findings would suggest that acromicria should not be considered a major diagnostic criterion for PWS in African Americans.

Butler et al. ' suggested that "there is an apparent paucity of African Americans with this disorder" and that this may be secondary to under- reporting. Perhaps African Americans with PWS are not being recognized because their appearance is less characteristic and acromicria is not apparent.

The number of African American patients we have evaluated is too small, and the range of ages at presentation to us is too wide to determine whether the absence of typical craniofacial findings, short stature and small hands and feet, significantly affects age at diagnosis. Because early intervention seems to allow improved medical and behavioral outcome, ${ }^{11}$ recognition that age at diagnosis in African American individuals may be older than that in white individuals would allow assessment of whether different diagnostic criteria should be used in nonwhite individuals. This determination will await assessment of larger numbers of patients in minority groups.

In conclusion, African American patients with PWS may not exhibit the typical craniofacial features or small hands and feet. This makes 
them less likely to meet diagnostic criteria or to be readily recognized as affected. Therefore, the clinician's threshold for suspicion of PWS should be lower in African American individuals with hypotonia and developmental delays.

\section{References}

1. Holm VA, Cassidy SB, Butler MG, Hanchett IM, Greenswag LR, Whitman BY et al Prader-Willi syndrome: Consensus diagnostic criteria. Pediatrics 1993;91:398-402.

2. American Society of Human Genetics/American College of Medical Genetics Test and Technology Transfer Committee. Diagnostic testing for Prader-Willi and Angelman syndromes: Report of the ASHG/ACMG Test and Technology Transfer Committee. Am J Hum Genet 1996;58:1085-1088.

3. National Center for Health Statistics. NCHS growth curves for children, birth-18 years, United States. Vital and Health Statistics. Series 11, No. 165. DHEW Publication No. Public Health Service. Washington: US Government Printing Office, 1997;78-7650.

4. Feingold M, Bossert WH. Normal values for selected physical parameters: An aid to syndrome delineation. Birth Defects: Original Article Series 1974;10.

5. Blais MM, Green WT, Anderson M. Lengths of the growing foot. I Bone Joint Surg Am 1956;38A:998-1000.

6. Golden WL, Hanchett JM, Breslin N, Steele MW. Prader-Willi syndrome in black females. Clin Genet 1984;26:161-163.

7. Butler MG, Weaver DD, Meaney FJ. Prader-Willi syndrome: Are there population differences? Clin Genet 1982;22:292-294.

8. Norman DM. Prader-Willi syndrome in a black: First case report. J Am Osteopath Assoc 1979;79:89-90.

9. Hudgins L, Cassidy SB. Hand and foot length in Prader-Willi syndrome. Am J Med Genet 1991;41:5-9.

10. National Center for Health Statistics. Body dimensions and proportions, white and negro children 6-11 years, United States. Vital and Health Statistics. Series 11, No. 143. DHEW Publication No. (HRA) Washington: US Government Printing Office, 1974; 75- 1625 .

11. Cassidy SB. Prader-Willi syndrome: Syndrome of the month. J Med Genet 1997;34:917-923. 